\title{
PATTERN OF MORBIDITY AND MORTALITY IN LBW NEONATES: A STUDY FROM JAIPUR
}

Mukesh Kumar Guptaํㅜ, Munish Kakkar², Chirag Sethi³ ${ }^{3}$ A. K. Malhotra ${ }^{4}$

\section{HOW TO CITE THIS ARTICLE:}

Mukesh Kumar Gupta, Munish Kakkar, Chirag Sethi, A. K. Malhotra. "Pattern of Morbidity and Mortality in LBW Neonates: A Study from Jaipur". Journal of Evolution of Medical and Dental Sciences 2014; Vol. 3, Issue 06, February 10; Page: 1339-1345, DOI: 10.14260/jemds/2014/1989

ABSTRACTS: The Low Birth Weight (LBW) is important factor affecting maternal and child health. This study was conducted to assess the morbidity and mortality patterns of LBW neonates at a tertiary care hospital in Jaipur, Rajasthan. 200 low birth weight babies out of 957 neonates born at our institute were included. Incidence of LBW babies was 20.9\%. Hyperbilirubinemia (30.5\%) was the commonest morbidity followed by respiratory distress (28.5\%) and sepsis (23.5\%). Preterm SGA babies had maximum morbidities. Mortality among LBW babies was $12.5 \%$ during hospital stay. There was significant decline in mortality with increasing gestational age. Mortality was maximum in initial 72 hours of life. Among the various causes of deaths sepsis accounted for $36 \%$ followed by respiratory distress $32 \%$. Among maternal factors extremes of maternal age, parity and bad obstetric history had significant relationship with incidence of LBS babies, morbidity and mortality among LBW babies.

KEYWORDS: Low birth weight, Neonates, Mortality and morbidity.

INTRODUCTION: Low birth weight (LBW) is associated with fetal and perinatal morbidity and mortality. The world health organization has defined 'low birth weight 'as babies whose birth weight is $<2500$ grams, irrespective of duration of gestation. ${ }^{1}$ Worldwide, $98 \%$ of all neonatal deaths occur in developing countries and are largely due to infections (32\%), birth asphyxia (29\%), and consequences of prematurity and congenital anomalies $(34 \%)^{2}$

Prevalence of LBW babies is highest in South Asian region and accounts $50 \%$ of all low birth weight babies. ${ }^{3}$ India, the second most populous country of the world, LBW continues to remain one of the serious challenges to maternal and child health care with every 3rd born child being of a low birth weight. ${ }^{4}$ It is important to monitor birth weights as well as assess the magnitude of neonatal morbidity and mortality and its subsequent causes and predisposing factors in order to prevent it. Currently nationwide data on neonatal morbidity and mortality in LBW babies are scarce, more so in backward states like Rajasthan. Hence, we conducted this study to have data on neonatal morbidity and mortality in Rajasthan.

MATERIAL \& METHODS: This prospective observational study was carried out at department of pediatrics, Mahatma Gandhi Medical College \& Hospital, Jaipur. Study population was all babies born during June 2010- July 2011at our institute weighing $<2.5 \mathrm{~kg}$ at birth. We excluded babies with birth weight $>2.5 \mathrm{Kg}$, out born babies, neonates with major congenital malformation, babies born <24wks gestation and weighing $<500 \mathrm{gm}$ at birth. All relevant maternal data including were obtained and recorded apart from relevant past and present obstetric history from the mothers file and antenatal records. All the minute details of the delivery and relevant factors were obtained and recorded. 
The newborn were observed from the time of delivery till its discharge from the hospital and all the details of events in cases of morbidity or mortality were collected. A detailed examination was carried in the neonatal unit in thermo neutral environment: immediately after birth and within 24 hrs. \& at discharge. Each baby was subjected to weight, length, head circumference and chest circumference. Weight was measured with electronic weighing machine (accuracy of \pm 10 grams). Babies were weighed naked immediately after birth and the weight was recorded in grams to the nearest of 10 grams. Weight was taken \& plotted an LUBCHENCO's intrauterine growth charts to classify as SGA and AGA. ${ }^{5}$ Recumbent length (Crown to heel length) was recorded with the help of infant meter. The reading was recorded to the nearest of $0.5 \mathrm{~cm}$ and was taken 24 hours after birth. Gestational Age was calculated by applying New Modified Ballard Score to the neonate.

These neonates were followed up for 1 month for assessment of morbidity \& mortality. Diagnosis of various disease states was made on the basis of clinical presentation and available and feasible laboratory and other investigations. The criteria and definitions of neonatal morbidities were based on the recommendations of National Neonatology Forum of India. ${ }^{6}$ In case of mortality of the infant the probable cause of death was recorded and verbal autopsy was done whenever there was any doubt as autopsies could not be done.

RESULTS: This study was conducted during June 2010- July 2011 at our institute. Total 957 babies were born during this period of these 200 babies were low birth weight ( 2500 grams) babies. Table 1 shows the distribution of LBW babies according to their gestational age. It is evident that the maximum number of babies 79 (39.5\%) were weighing between 1500-1999 grams while minimum number of babies 10 (5\%) were weighing less than 1000 grams. Maximum number of babies 61 $(30.5 \%)$ were of the gestational age 31-34 weeks while only 12 (6\%) babies were born before 28 weeks.

\begin{tabular}{|c|c|c|c|c|c|c|c|c|}
\hline Weight (gm.) & \multicolumn{2}{|c|}{$\begin{array}{c}\mathbf{1 0 0 0} \\
\mathbf{N}\end{array}$} & \multicolumn{1}{c|}{$\begin{array}{c}\mathbf{1 0 0 0 - 1 4 9 9} \\
\text { N \% }\end{array}$} & \multicolumn{2}{c|}{$\begin{array}{c}\mathbf{1 5 0 0 - 1 9 9 9} \\
\text { N \% }\end{array}$} & \multicolumn{2}{c|}{$\begin{array}{c}\mathbf{2 0 0 0 - 2 4 9 9} \\
\mathbf{N} \%\end{array}$} \\
\hline$<28$ wks. & 7 & 58.3 & 5 & 41.6 & - & - & - & - \\
\hline $29-30$ wks. & 2 & 9.6 & 17 & 65.3 & 7 & 27 & - & - \\
\hline $31-34$ wks. & 1 & 1.6 & 24 & 39.3 & 23 & 37.7 & 13 & 21.3 \\
\hline $35-37$ wks. & - & - & 7 & 12.5 & 29 & 51.7 & 20 & 35.7 \\
\hline$>37$ wks. & - & - & - & - & 20 & 44.4 & 25 & 55.5 \\
\hline Total & 10 & 5 & 53 & 26.5 & 79 & 39.5 & 58 & 29.0 \\
\hline
\end{tabular}

Table 1: Distribution of LBW babies according to gestational age

\begin{tabular}{|l|l|l|l|l|}
\hline Classification of Neonates & Term AGA & Term SGA & Preterm & PT SGA \\
\hline Distribution of LBW neonates (n=200) & $23(11.5 \%)$ & $31(15.5 \%)$ & $39(19.5 \%)$ & $107(53.5 \%)$ \\
\hline Maternal age (n) & & & & \\
$-<20$ yrs. $(29,14.5 \%)$ & $02(6.8 \%)$ & $05(17.2 \%)$ & $08(27.5 \%)$ & $14(48.2)$ \\
$-21-25$ yrs. $(97,48.5 \%)$ & $21(21.6 \%)$ & $14(14.4 \%)$ & $19(19.5 \%)$ & $43(44.3 \%)$ \\
$-26-30$ yrs. $(61,30.5 \%)$ & $06(19.8 \%)$ & $11(18 \%)$ & $17(27.8 \%)$ & $27(44.2 \%)$ \\
$->30$ yrs. $(13,6.5 \%)$ & $04(30.7 \%)$ & $02(15.3 \%)$ & $4(30.7 \%)$ & $03(23 \%)$ \\
$X^{2}=73.613$ as df $=3, p<<0.05$ & & & & \\
\hline
\end{tabular}




\begin{tabular}{|l|l|l|l|l|}
\hline Relation of parity of mother & $09(39.2 \%)$ & $14(45.2 \%)$ & $11(28.2 \%)$ & $51(47.6 \%)$ \\
-Primi $(85,42.5 \%)$ & $08(34.7 \%)$ & $10(32.2 \%)$ & $13(33.3 \%)$ & $40(37.3 \%)$ \\
-Multi $(71,35.5 \%)$ & $06(26 \%)$ & $07(22.5 \%)$ & $15(38.4 \%)$ & $16(15 \%)$ \\
-Grand Multi (44, 22\%) & & & \\
$X^{2}=12.243, \mathrm{df}=3 ; \mathrm{p}<0.05$ significant & & & \\
\hline \multicolumn{4}{|c|}{ Table 2: Distribution of babies according to their weight for } \\
gestational age and relationship with maternal age and parity
\end{tabular}

MATERNAL FACTORS AND LBW BABIES: Maternal age: Association between maternal age \& gestational age of baby is statistically highly significant (table 2) Majority (48.2\%) of the LBW babies born to mothers $<20$ years were preterm SGA. Association between maternal age \& birth weight of babies is statistically significant $(\mathrm{p}<0.005)$. Almost half of the LBW babies $(\mathrm{n}=97,48.5 \%)$ were born to mother between $21-25$ years of age and $14.5 \%$ were born to the mothers $<20$ years. The incidence of VLBW (babies weighing $<1499 \mathrm{gm}$.) was also maximum in the mothers $<20$ years of age.

Parity: Majority (64.5\%) of the LBW babies were born at the two extremes of birth order i.e. primiparous women and grand-para. $42.5 \%$ babies were born to the primi and $22 \%$ to grand multipara (table 3). Among the term SGA babies 46\% were born to primi mothers and among preterm SGA babies $47.6 \%$ were born to primi mothers. These observations were stat1istically significant.

Only $68.5 \%(n=137)$ mothers had antenatal checkups. 39.5\% (n=79) mothers were from urban areas and rest was from rural areas. There was high incidence of bad obstetric record among mothers with LBW babies which is evident by the fact that only $38(33.04 \%)$ mothers of LBW babies were found to have normal previous obstetric record. while $23.4 \%$ had abortions, $9.5 \%$ had still births, $15.5 \%$ had preterm deliveries and $18.2 \%$ had previous neonatal deaths. These observations were significant statistically (p). There was high prevalence of other maternal risk factors like anemia (33.5\%), hypertension (12.5\%), ante partum hemorrhage (10\%), premature rupture of membranes (28.5\%), idiopathic preterm labor (23.5\%), chronic medical illnesses (7\%) multiple factors (19\%).

\section{Morbidities in LBW babies}

\begin{tabular}{|l|c|c|c|c|c|}
\hline \multicolumn{1}{|c|}{ Morbidity } & $\begin{array}{c}\text { Total Cases } \\
\mathbf{n = 2 0 0} \mathbf{2 \% )}\end{array}$ & $\begin{array}{c}<\mathbf{1 0 0 0} \\
\mathbf{n = 1 0} \mathbf{1 \% )}\end{array}$ & $\begin{array}{c}\mathbf{1 0 0 0 - 1 4 9 9} \\
\mathbf{n = 5 3}(\mathbf{6})\end{array}$ & $\begin{array}{c}\mathbf{1 5 0 0 - 1 9 9 9} \\
\mathbf{n =} \mathbf{7 9}(\mathbf{6})\end{array}$ & $\begin{array}{c}\mathbf{2 0 0 0 - 2 4 9 9} \\
\mathbf{n = 5 8} \mathbf{5 \%})\end{array}$ \\
\hline Respiratory Distress & $57(28.5 \%)$ & $8(80 \%)$ & $18(33.9 \%)$ & $18(22.7 \%)$ & $30(21 \%)$ \\
\hline HMD & $29(40.5 \%)$ & $7(70 \%)$ & $14(26.4 \%)$ & $7(8.8 \%)$ & $1(1.7 \%)$ \\
\hline TTNB & $11(5.5 \%)$ & $-(\%)$ & $1(1.8 \%)$ & $4(5 \%)$ & $6(10.2 \%)$ \\
\hline Pneumonia & $10(5 \%)$ & $1(10 \%)$ & $3(5.4 \%)$ & $4(5 \%)$ & $2(3.4 \%)$ \\
\hline MAS & $7(3.5 \%)$ & $-(\%)$ & & $3(3.8 \%)$ & $4(6.8 \%)$ \\
\hline Septicemia & $47(23.5 \%)$ & $6(60 \%)$ & $17(32 \%)$ & $19(24 \%)$ & $5(8.5 \%)$ \\
\hline Recurrent Apnea & $27(13.5 \%)$ & $7(70 \%)$ & $9(16.9 \%)$ & $9(11.3 \%)$ & $2(3.4 \%)$ \\
\hline NEC & $17(8.5 \%)$ & $5(50 \%)$ & $7(13.2 \%)$ & $5(6.3 \%)$ & - \\
\hline Jaundice (NNJ) & $61(30.5 \%)$ & $4(40 \%)$ & $21(39.6 \%)$ & $23(29.1 \%)$ & $13(22 \%)$ \\
\hline Seizures & $17(8.5 \%)$ & $3(30 \%)$ & $7(13.2 \%)$ & $6(7.5 \%)$ & $1(1.7 \%)$ \\
\hline Intracranial & $5(2.5 \%)$ & $1(10 \%)$ & $2(3.6 \%)$ & $2(2.5 \%)$ & - \\
\hline
\end{tabular}


ORIGINAL ARTICLE

\begin{tabular}{|l|c|c|c|c|c|}
\hline Hemorrhage (ICH) & & & & & \\
\hline Hypothermia & $27(13.5 \%)$ & $3(30 \%)$ & $11(20.7 \%)$ & $11(13.92 \%)$ & $3(5.1 \%)$ \\
\hline $\begin{array}{l}\text { Metabolic } \\
\text { Disorders }\end{array}$ & $17(8.5 \%)$ & $4(40 \%)$ & $7(13.2 \%)$ & $5(6.3 \%)$ & $1(1.7 \%)$ \\
\hline Perinatal Asphyxia & $19(9.5 \%)$ & $2(20 \%)$ & $7(13.2 \%)$ & $6(7.5 \%)$ & $4(6.8 \%)$ \\
\hline Polycythemia & $10(5.0 \%)$ & $2(20 \%)$ & $4(7.2 \%)$ & $4(5 \%)$ & - \\
\hline
\end{tabular}

Table 3 shows the incidence of various neonatal problems among LBW infants. hyperbilirubinemia was major cause of morbidity (30.5\%) followed by respiratory distress (28.5\%) and septicemia 47 (23.5\%). Among babies <1000 gm., RDS accounts for $80 \%$ of morbidity, while recurrent apnea, sepsis and Hyperbilirubinemia accounts for 70\%, 60\%, 40\% of morbidities respectively. Those who weighed between 1000-1499 gm., Hyperbilirubinemia accounted for 40\% of morbidity followed by RDS and sepsis accounting 34\% and 32\% respectively. Among the babies weighing between 1500-1999gms, similar pattern was observed, hyperbilirubinemia followed by RDS \& sepsis, while babies between 2000-2499gms; TTNB (11\%) was the most common morbidity.

On analysis of morbidities according to weight for gestational age maximum morbidity (81\%) was seen among preterm SGA babies and least in the term AGA babies (30.4\%). Out Among the babies with RDS $60 \%$ were preterm and among the babies with septicemia $68 \%$ were preterm while among the babies with hyperbilirubinemia $76 \%$ were preterm SGA. In the babies with gestation age $<28$ wks., HMD (60\%) was major cause of morbidity followed by hyperbilirubinemia, sepsis and recurrent apnea which accounted for morbidities in 56\%, 50\%, 50\% babies respectively. Incidence of HMD, decreased with increase in gestational age and incidence reaches to about $1 \%$ in gestational age $>35$ wks. Similarly incidence of septicemia, hyperbilirubinemia, NEC decreases significantly with increase in gestational age. Approximately $80 \%$ of cases of polycythemia and ICH occurred in gestational age of $<34$ wks and $84 \%$ of cases of hypothermia occurred in gestational age of $<34$ wks., while incidence of MAS is $72 \%$ in gestational age of $>34 w k s$.

Age of the infant at the time of death and incidence of mortality: We observed that mortality in babies weighing $<1000 \mathrm{gm}$ was $50 \%$. In babies between $1000-1499 \mathrm{gm}$ it was $16.9 \%$. In $1500-$ 1999gm 8.8\% and in 2000 - 2499gm it was 6.8\% died. Out of 25 deaths, 8 (24\%) occurred within 24 hours of birth, 9 (36\%) within 24-72 hours and 7 (28\%) 72 hours to 7 days. Age of 4 infants was more than 7 days at the time of death. Proportion of babies dying within 24 hours of birth was maximum in the weight group below < 1000 (60\%) while proportion of babies dying within 24-72 hrs. of birth maximum in weight group between (1500-1999gms). Incidence of mortality was maximum in babies weighing < 1000 gm. (50\%) and decreases with increase in weight of babies.

Among the various causes of deaths septicemia accounted for 36\%, followed by RDS which accounts for 32\%. The major cause of death in ELBW groups was HMD which accounts for almost $80 \%$ of deaths. In VLBW babies septicemia and HMD jointly accounted for almost $30 \%$ of deaths. In babies weighing 1500-2499 grams, septicemia accounted for almost 50\% of total death as the primary cause of death. 
DISCUSSION: In the present study 200 singleton LBW babies born out of consecutive deliveries at Mahatma Gandhi Hospital, Jaipur during June-2010 - 2011 were studied. Our center is catering maternity services to the population of Jaipur and nearby rural areas. A large number of these mothers fall in the criteria of high risk pregnancies like pregnancies with medical illness, early or advanced maternal age and cases requiring instrumentation or caesarean section.

Incidence of LBW babies reported previously varies from $24-30 \%$ however it was $20.2 \%$ (200 cases out of 970 live births) at our center which is little lower. ${ }^{7-10}$ Lack of prenatal care or irregular prenatal care has been found to be associated with high incidence of lower birth weight deliveries, prematurity, morbidities and high mortality. ${ }^{11-13}$ It is surprising that even in this era only $68.7 \%$ mothers were attending antenatal clinics. The incidence of Low Birth Weight babies had significant relationship with maternal age and parity $(\mathrm{p}<0.005)$. Majority of mother $(48.5 \%)$ were young and there was significant association between parity and Low Birth Weight $(\mathrm{p}<.005)$. Both extremes of age in mother were associated with high incidence of LBW babies (42.5\% babies born to primi gravida and 22\% born to grand multipara). High incidence of Low Birth Weight babies was observed in primipara $(42.5 \%)$ \& grand multipara $(22 \%)$. Roy et al and other workers showed significant association of maternal age \& LBW in 2006.11-17 We also had similar findings as majority of mother (48.5\%) were young and there was significant association between parity and Low Birth Weight $(\mathrm{p}<.005)$. Both extremes of age in mother were associated with high incidence of LBW babies (42.5\% babies born to primi gravida and $22 \%$ born to grand multipara). ${ }^{11-17}$

We observed a statistically significant $(\mathrm{P}<0.005)$ high incidence of bad obstetric record in mothers delivering LBW babies as only 38 of 115(33.04\%) had normal previous obstetric record and rest (67\%) had previous bad obstetric history was significant relationship between previous obstetric history \& LBW babies $(\mathrm{p}<0.005)$. Abner et al observed that mothers with previous fetal death have a significantly higher incidence of LBW birth. ${ }^{11} \mathrm{~A}$ premature first birth is highly predictive of preterm birth or IUGR during second pregnancy.12 The same was observed by many other authors. ${ }^{17,18}$ Sixty two percent babies suffered from illnesses in the immediate post-natal period in our study. The morbidity was more in preterm SGA (81\%) as compared to preterm AGA (43.5\%) and term SGA (41.9\%). Narayan $S$ et al in their study observed hyperbilirubinemia was most common reason infant morbidity, which was similar to our study showing $30.5 \%$ having hyperbilirubinemia. ${ }^{17}$

Gestational age was found to be better predictor of the pattern of morbidity in comparison to birth weight however we had almost similar patterns of mortality has been reported by various other workers in our country. ${ }^{17-23}$

The first 4 weeks of life, the neonatal period carries one of the highest risks of death of any 4week period in the human lifespan. ${ }^{20}$ Mortality was high in first 72 hours. It was $60 \%$ as compared to $40 \%$ after 72 hours of age. In our study, the main causes in order of frequency were: hyaline membrane disease (32\%), septicemia (35\%), birth asphyxia (8\%), followed by pulmonary hemorrhage $(8 \%)$. There was significant decline in mortality with the increasing gestational age evidenced by the fact that mortality in babies in $<28$ weeks in our study was 44\%, in 29-30 weeks it was $26 \%$, in $31-34$ weeks $9.6 \%$ \& only $7 \%$ in babies > 35 weeks of gestation. Therefore $32-34$ week gestational age emerges as an important transition period, critical for neonatal morbidity and mortality. Thus all efforts should be made to salvage these babies in NICU'S. Similar observations were reported by Bhatia et al, Bhakoo and Sarna. Fernando and Paul considered gestational age of 32 
completed weeks to be the critical point above which significantly fewer incidences of morbidity and mortality can be expected.

Similar incidence of mortality has been reported by various other workers in our country. Mortality was high in babies born to mothers, who did not received antenatal care (17.5\%) compared to those who received antenatal care. It showed a significant association $(p<0.005)$. Higher incidence of mortality was seen in mothers who had bad obstetric history.

Study of Singh M et al has shown improved survival with increase in both the birth weight and gestational age. Our study results were in accordance with Singh et al showing $100 \%$ mortality in babies with a birth weight of 500-999gms. ${ }^{20}$

Overall our study provides data from our state which are similar to other studies and reiterates the need to improve prenatal and neonatal services.

\section{REFERENCES:}

1. WHO, UNICEF. Low birthweight: country, regional and global estimates. Geneva, UNICEF and WHO, 2004.

2. Moss W, Darmstadt GL, Marsh DR, Black RE, Santosham M. J Perinatol 2002; 22:484-95.

3. UNICEF (2008). State of world children 2008.

4. Bhargava SK, Singh KK, Saxena BN.ICMR Task Force National Collaborative Study on Identification of High Risk Families, Mothers and Outcome of their Off-springs with particular reference to the problem of maternal nutrition, low birth weight, perinatal and infant morbidity and mortality in rural and urban slum communities. Summary, conclusions and recommendations. Indian Pediatr. 1991; 28:1473-80.

5. Lubchenco LO. Neonatal mortality rate: relationship to birth weight and gestational age. Journal of Pediatrics 1972:81 814-22.

6. Evidence Based Clinical Practice Guidelines. National Neonatology Forum India 2010.

7. Kumar GV, Georgeen AJ, and Viswanatha Kumar HM. Evaluation of Neonatal Morbidity and Mortality in Low Birth Weight Babies in a Tertiary Care Hospital. Research J Pharma Biol Chem Scienc 2013: 4; 481-85.

8. Dhankar M, Rawat A.K., Varun. Outcome in Low Birth Weight Newborns. International Journal of Basic and Applied Medical Sciences ISSN: 2277-2103 (Online) Available at http://www.cibtech.org/jms.htm 2013:3; 39-43.

9. Suhas V Patil, Dhananjay Y Shrikhande, Gurmit Singh, Purushottam A Giri. Pattern of neonatal mortality and morbidity in LBW neonates: a study from a tertiary care hospital in rural India. International Journal of Students' Research 2011:1 (4); 123-128.

10. Kumar M, Paul VK, Kapoor SK, Anand K, AK. Neonatal outcomes at a subdistrict hospital in north India. J Trop Pediatr. 2002; 48:43-46.

11. Levkoff AH, Westphal M, Miller MC 3rd, Michel Y. Maternal risk factors in infants with very low birth weight. Obstet Gynecol. 1982; 60:612-6.

12. Sharma M, Kumar D, Huria A, Gupta D. Maternal Risk Factors Of Low Birth Weight In Chandigarh India. The Internet Journal of Health 2009, 9 (1)

13. Roy KK, Baruah J, Kumar S, Malhotra N, Deorari AK, Sharma JB. Maternal antenatal profile and immediate neonatal outcome in VLBW and ELBW babies. Indian J Pediatr. 2006; 73:669-73. 
14. Deshmukh SS, Motghare DD, Zodpey SP, Wadhva SK. A study of low birth weight and associated maternal factors in urban area, Indian Paediatrics, 1998 35: 7-10.

15. Choudhary P. A study of maternal and neonatal factors in relation to perinatal mortality. Indian Pediatrics 1981: 48 297-304.

16. Kumari S, Shendurnikar N, Jain S, Kanodia K, Jain R and Mullick DN. Outcome of low birth weight babies with special reference to some maternal factors. Indian Pediatrics 1989:26 10634.

17. Narayan S, Agrawal R, Upadhyay A, Deorari AK, Singh M and Paul VK. Survival and morbidity in extremely low birth weight (ELBW) infants. Indian Pediatrics 2003:40 130-5.

18. Das BK, Mishra RN, Mishra OP, Bhargava V and Prakash A. Comparative outcome of low birth weight babies. Indian Pediatrics 1993:30 15-21.

19. Paul B, Saha I, Mukherjee A, Biswas R, Roy S, Chaudhuri RN. Morbidity pattern of low-birthweight infants in an urban slum of Kolkata, India. J Egypt Public Health Assoc. 2011; 86 (34):39-43. doi: 10.1097/01.EPX.0000399137.11413.e0.

20. Singh M. Birth weight, gestational age correlation neonatal mortality. Indian Paediatrics 1982: $49511-7$.

21. Sarna MS, Saili A, Dutta AK, Kumari S. Neonatal mortality patterns in an urban hospital. Indian Pediatr. 1991; 28:719-24.

22. Basu S, Rathore P, Bhatia BD. Predictors of mortality in very low birth weight neonates in India. Singapore Med J. 2008; 49:556-60.

23. Kaushik SL, Parmar VR, Grover N and Kaushik R. Neonatal mortality rate: relationship to birth weight and gestational age. Indian Journal of Pediatrics 1998: 65 429-33.

\section{AUTHORS:}

1. Mukesh Kumar Gupta

2. Munish Kakkar

3. Chirag Sethi

4. A. K. Malhotra

\section{PARTICULARS OF CONTRIBUTORS:}

1. Associate Professor, Department of Pediatrics, Mahatma Gandhi Medical College, Jaipur.

2. Professor, Department of Pediatrics, Mahatma Gandhi Medical College, Jaipur.

3. Resident, Department of Pediatrics, Mahatma Gandhi Medical College, Jaipur.
4. Professor, Department of Pediatrics, Mahatma Gandhi Medical College, Jaipur.

NAME ADDRESS EMAIL ID OF THE CORRESPONDING AUTHOR:

Dr. Mukesh Kumar Gupta, 61-226, Sector, Pratap Nagar, Sananer, Jaipur - 302033.

E-mail: drmukeshgupta.pediatrics@gmail.com

Date of Submission: 15/01/2014. Date of Peer Review: 16/01/2014. Date of Acceptance: 27/01/2014. Date of Publishing: 04/02/2014. 